\title{
Intrarectal administration of oxygenated perfluorodecalin promotes healing of murine colitis by targeting inflammatory hypoxia
}

\author{
Pieter Hindryckx ${ }^{1}$, Lindsey Devisscher ${ }^{1}$, Debby Laukens ${ }^{1}$, Koen Venken ${ }^{2}$, Harald Peeters ${ }^{1}$ and Martine De Vos ${ }^{1}$
}

Intestinal inflammation is associated with enhanced mucosal hypoxia, which contributes to the ongoing inflammatory process and hampers appropriate mucosal healing. We questioned whether local treatment with an oxygen $\left(\mathrm{O}_{2}\right)$-carrying and -releasing molecule (oxygenated perfluorodecalin, $\mathrm{O}_{2}-\mathrm{PFD}$ ) could positively influence the course of experimental colitis. The impact of intrarectal (IR) treatment with $\mathrm{O}_{2}$-PFD was tested using the murine dextran sodium sulfate (DSS)induced model of distal colitis, both in preventive and therapeutic settings. Colonic mucosal hypoxia was visualized by pimonidazole staining. Colonic permeability was evaluated with FITC-dextran. In the preventive study, mice treated with $\mathrm{O}_{2}$-PFD were protected against DSS colitis compared with saline-treated mice, as demonstrated by reduced shortening of colon length, reduced colonic tumor necrosis factor-alpha levels and a lower histological inflammation score $(P<0.05$ for all parameters). In the therapeutic study, administration of $\mathrm{O}_{2}-\mathrm{PFD}$ resulted in accelerated recovery of colitis compared with saline-treated littermates, and this was reflected by a better weight evolution, lower myeloperoxidase activity and a lower histological inflammation score $\left(P<0.05\right.$ for all parameters). It was found that $\mathrm{O}_{2}$-PFD established its therapeutic effects through (1) intrinsic anti-inflammatory effects of the PFD molecule and (2) $\mathrm{O}_{2}$-induced preservation and healing of the intestinal epithelial surface. Further in vitro and in vivo studies showed that the barrier-protective activity of $\mathrm{O}_{2}$-PFD was obtained through prevention of colonocyte apoptosis and stimulation of colonocyte proliferation during inflammatory hypoxia. These data show that IR treatment with $\mathrm{O}_{2}-\mathrm{PFD}$ promotes colitis healing by the combined actions of direct anti-inflammatory effects and $\mathrm{O}_{2}$-induced restitution of the epithelial barrier. As such, $\mathrm{O}_{2}-\mathrm{PFD}$ enemas could be an attractive treatment option for patients with distal inflammatory bowel disease.

Laboratory Investigation (2011) 91, 1266-1276; doi:10.1038/labinvest.2011.102; published online 27 June 2011

KEYWORDS: experimental colitis; intestinal epithelium; mucosal hypoxia; perfluorodecalin

Intestinal inflammation is associated with low mucosal oxygen $\left(\mathrm{O}_{2}\right)$ levels, likely because of the combined effects of increased metabolic demand and vascular dysfunction. The colonocytes that form the barrier of the gut are the first cells to suffer from mucosal hypoxia during inflammation. These cells have a marginal baseline $\mathrm{O}_{2}$ supply, and if $\mathrm{PO}_{2}$ levels decrease below a critical threshold, reduced proliferation and increased apoptosis occurs, respectively, resulting in delayed mucosal healing and further disruption of the epithelial barrier. $^{1,2}$ The importance of mucosal hypoxia in the etiopathogenesis and maintenance of inflammation in patients with inflammatory bowel disease (IBD) has recently garnered attention. ${ }^{3,4}$ Tissue hypoxia not only hampers appropriate mucosal healing but also promotes ongoing inflammation by stimulating the release of proinflammatory cytokines such as tumor necrosis factor-alpha (TNF- $\alpha){ }^{5,6}$ We and others have shown that the intestinal epithelium can be protected against inflammatory hypoxia by boosting their hypoxia-induced adaptive response, using pharmacological prolyl hydroxylase inhibitors. $^{7}$

Another potential tool to defend the gut epithelium against hypoxia during mucosal inflammation is by directly delivering exogenous $\mathrm{O}_{2}$ to the intestinal mucosa.

In this context, hyperbaric $\mathrm{O}_{2}$ therapy $(\mathrm{HBO})$ has shown to be beneficial in animal models of IBD, as well as in human ulcerative colitis (UC) and Crohn's disease (CD). ${ }^{8-11}$ The beneficial effects of $\mathrm{HBO}$ are believed to be because of improved tissue oxygenation, enhanced tissue repair and

${ }^{1}$ Department of Gastroenterology, Ghent University Hospital, Ghent, Belgium and ${ }^{2}$ Department of Rheumatology, Ghent University Hospital, Ghent, Belgium Correspondence: Dr P Hindryckx, MD, PhD, Department of Gastroenterology, Ghent University Hospital, De Pintelaan 185, 3K12IE, Ghent B-9000, Belgium. E-mail: Pieter.Hindryckx@UGent.be 
direct anti-inflammatory actions. However, $\mathrm{HBO}$ is not readily available, as it is expensive and may cause serious side effects, which preclude its routine clinical use.

Perfluorocarbons (PFCs) are highly hydrophobic, fluorinated organic solutions with a high solubility coefficient for $\mathrm{O}_{2}$. In contrast to hemoglobin, which carries $\mathrm{O}_{2}$ by chemical binding, PFCs physically solubilize $\mathrm{O}_{2}$. Consequently, $\mathrm{O}_{2}$ that is captured by PFCs can be easily released again, according to a linear relationship with the $\mathrm{O}_{2}$ partial pressure $\left(\mathrm{PO}_{2}\right)$ gradient. ${ }^{12-16}$

Perfluorodecalin (PFD) is an example of PFC. It is an odorless and colorless high-density liquid with a remarkable capacity to dissolve high amounts of $\mathrm{O}_{2}$ (up to 50-60 vol\%). As such, PFD can be used as a powerful carrier to deliver $\mathrm{O}_{2}$ to ischemic tissues. ${ }^{13}$ The clinical benefit of topical $\mathrm{O}_{2}$ application has already been demonstrated in patients with difficult-to-treat chronic wounds like diabetic foot ulcers. ${ }^{17,18}$ Moreover, intraluminal administration of oxygenated PFCs has previously been reported to improve the outcome of experimental ischemia-reperfusion injury of the gut by protecting intestinal mucosal function and integrity. ${ }^{19,20}$ In addition, intraperitoneally (i.p.) administered $\mathrm{O}_{2}$-PFD in rats inhibits bacterial translocation during severe pancreatitis by protecting the intestinal barrier through decreased intestinal epithelial apoptosis. ${ }^{21}$ Despite the evidence of beneficial effects of $\mathrm{O}_{2}$-PFD on wound healing and barrier function of the gut, the application of this molecule has not yet been evaluated in inflammatory barrier diseases such as CD and UC. In this study, we investigated the effects of intrarectal (IR) $\mathrm{O}_{2}$-PFD treatment on experimental colitis.

\section{MATERIALS AND METHODS}

\section{Mice and Induction of Colitis}

Eight-week-old Sv129 mice received 4\% dextran sulfate sodium salt (DSS, MP Biomedicals, Illkirch, France) in their drinking water for seven consecutive days to induce colitis. ${ }^{2}$ All mice were treated according to the Institutional Animal Health Care Guidelines, following study approval by the Institutional Review Board at the Faculty of Medicine and Health Sciences of Ghent University.

\section{Perfluorodecalin Oxygenation}

Perfluorodecalin (>99\% purity, F2 Chemicals, Lancashire, UK) was oxygenated by a 5 -min bubbling with $100 \% \mathrm{O}_{2}$ at a rate of $3 \mathrm{l} / \mathrm{min}$, using a standard $\mathrm{O}_{2}$ bottle as previously described. ${ }^{19}$

\section{$\mathrm{PO}_{2}$ Measurement}

The $\mathrm{PO}_{2}$ of $\mathrm{O}_{2}$-PFD and normal saline was measured with a Blood Gas Analyzer (Bayer Rapidlab 248, Holly, MI, USA), with a measuring range from 0 to $749 \mathrm{~mm} \mathrm{Hg}$.

\section{Experimental Approach}

Five experimental groups were included: (1) animals receiving DSS and IR administration of $\mathrm{O}_{2}$-PFD $(N=5-6$ for each experiment), (2) animals receiving DSS and IR administration of non- $\mathrm{O}_{2}$-PFD $(\mathrm{N}=5-6$ for each experiment $)$, (3) animals receiving DSS and IR administration of normal saline ( $\mathrm{NaCl}, N=5-6$ for each experiment), (4) control animals receiving IR PFD but no DSS $(N=3$ for each experiment) and (5) control animals receiving IR $\mathrm{NaCl}$ but no DSS ( $N=3$ for each experiment). All mice were treated twice daily under short isoflurane anesthesia $(0.5 \mathrm{ml}$ per administration).

In the first experiment (preventive setting), the animals received treatment the day before DSS administration and were killed at day 7 for analysis.

In the second experiment (therapeutic setting), animals first received DSS for 7 days and were then randomized into different treatment groups. Treatment began at day 7 and continued for 4 days. At day 11, animals were killed for analysis.

\section{Assessment of Histological Inflammation}

Sections of the distal colon were stained with hematoxylin and eosin. To assess histological inflammation, a previously validated scoring system was used. ${ }^{22}$ In short, colonic ulceration was scored based on the percentage of ulceration of the epithelial cell surface, with scores ranging from 0 (no ulcerations) to 4 (more than $75 \%$ ulceration). The inflammation score was based on increased mucosal and submucosal inflammatory cell infiltration, both ranging from 0 (no increase) to 3 (severely increased). The total histological inflammation score was calculated as the sum of the scores given to colonic ulcerations and inflammatory cell infiltration. Scoring was performed by two blinded observers (PH and $\mathrm{LD})$.

\section{Assessment of Intestinal Mucosal Hypoxia}

To demonstrate colonic mucosal hypoxia, we used the Hypoxyprobe-1 Plus Kit (NPI, MA, USA). Briefly, mice were injected with pimonidazole hydrochloride $(100 \mathrm{mg} / \mathrm{kg}$ in saline, i.p.), which rapidly diffuses out of the cells in the presence of normal $\mathrm{O}_{2}$ levels. Under conditions of inadequate $\mathrm{O}_{2}$ concentration, this molecule associates with intracellular proteins and can be immunohistochemically localized. ${ }^{1}$ Mice were killed at $1 \mathrm{~h}$ after pimonidazole injection. Semiquantitative computerized quantification of pimonidazolestained, paraffin-embedded distal colonic sections was performed, using Cell D software (Olympus Soft Imaging Solutions, Münster, Germany). Images $(\times 40)$ of the sections in their entirety were obtained and the total percentage of 3,3'-diaminobenzidine (DAB; Dako, Glostrup, Denmark) staining was assessed.

\section{Micro-Computed Tomography}

To trace IR-administered PFD, we used micro-computed tomography $(\mu \mathrm{CT})$ scans. Each scan was acquired in $2 \times 2$ binning mode, with a $50-\mu \mathrm{m}$ spot size, at $70 \mathrm{kVp}$ and $145 \mu \mathrm{A}$ in 512 projections using a magnification of 1.3 . CT acquisitions were analytically reconstructed using the Feldkamp algorithm 
to a $512 \times 512 \times 512$ matrix with $170 \mu \mathrm{m}$ voxels. All resulting images were analyzed with VIVID (Gamma Medica Ideas, Northridge, LA, USA) based on Amira.

\section{Measurement of Colonic Myeloperoxidase and TNF- $\alpha$ levels}

Distal colonic myeloperoxidase (MPO) activity was assessed as described earlier. ${ }^{2}$

Distal colonic TNF- $\alpha$ levels were measured by enzymelinked immunosorbent assay (Quantikine, R\&D, MN, USA) and normalized to total protein content following the manufacturer's manual.

\section{Measurement of Intestinal Epithelial Permeability}

Intestinal epithelial permeability was analyzed by measuring plasma FITC levels at $4 \mathrm{~h}$ after oral gavage of FITC-labeled dextran $(4 \mathrm{kDa}, 0.6 \mathrm{mg} / \mathrm{g}$ body weight), as previously described. ${ }^{23}$

\section{In Vivo Assessment of Intestinal Epithelial Cell Apoptosis and Proliferation}

In vivo assessment of intestinal epithelial cell (IEC) apoptosis and proliferation was performed with immunohistochemistry on paraffin-embedded distal colonic sections using caspase-3 and Ki-67 staining, respectively. Antigen retrieval was performed with citrate. After blocking endogenous peroxidase activity and nonspecific binding (using $3 \% \mathrm{H}_{2} \mathrm{O}_{2}$ for 10 min and Block buffer (Dako), respectively), the primary antibody was applied. For caspase-3 staining, a rabbit polyclonal anti-cleaved caspase-3 antibody was used (diluted 1:400 in TBST, overnight incubation at $4{ }^{\circ} \mathrm{C}$; Cell Signaling Technology, MA, USA). For Ki-67, a ready-to-use antibody rabbit monoclonal antibody was used (30 min incubation at room temperature, Thermo Scientific, IL, USA).

A secondary ready-to-use horseradish peroxidase-linked anti-rabbit antibody (Dako) was used for detection (30 min incubation at room temperature), after which the peroxidase was visualized with DAB. Computerized semi-quantitative analysis of the DAB-stained region was performed.

\section{In Vitro Intestinal Epithelial Apoptosis Assay}

HT29 cells (a human colon carcinoma epithelial cell line, HTB-38, ATCC Cell Biology Collection, VA, USA) were seeded in six-well plates, at $2 \times 10^{6}$ cells/well.

The cells were pretreated with $\mathrm{O}_{2}$-PFD ( $>99 \%$ purity), non- $\mathrm{O}_{2}$-PFD ( $>99 \%$ purity) or phosphate-buffered saline
(PBS) (diluted 1:3 in McCoy's medium) and subsequently exposed to atmospheric or $1 \% \mathrm{O}_{2}$ in a hypoxic chamber (Oxoid, Hampshire, UK) ${ }^{24}$ After overnight incubation, cells were harvested and apoptosis was quantified using a caspase3 activity assay (R\&D), following the manufacturer's manual.

\section{Annexin V Flow Cytometry}

HT29 cells were pretreated with $\mathrm{O}_{2}-\mathrm{PFD}$, non- $\mathrm{O}_{2}-\mathrm{PFD}$ or PBS and subsequently exposed to atmospheric or $1 \% \mathrm{O}_{2}$ in a hypoxic chamber (as described above). After overnight incubation, cells were harvested and stained with FITClabeled Annexin V, following the manufacturer's manual (BD Pharmingen, San Diego, CA, USA). Flow cytometric analysis was performed using a FACSCanto-II (Becton Dickinson, Mountain View, CA, USA), with results analyzed by means of FlowJo software (Tree Star, Ashland, OR, USA).

\section{In Vitro Intestinal Epithelial Proliferation Assay}

HT29 cells were seeded in 96-well plates, with each well containing 7500 cells. The cells were pretreated with $\mathrm{O}_{2}-\mathrm{PFD}$ ( $>99 \%$ purity), non- $\mathrm{O}_{2}-\mathrm{PFD}$ ( $>99 \%$ purity) or PBS (diluted in an equal volume of McCoy's medium) and subsequently exposed to atmospheric or $1 \% \mathrm{O}_{2}$. After an overnight incubation, the medium was refreshed (to a final volume of $100 \mu \mathrm{l} /$ well) and $20 \mu \mathrm{l}$ of 3-(4,5-dimethylthiazol-2yl)-2,5-diphenyltetrazolium bromide (MTT, $5 \mathrm{mg} / \mathrm{ml}$ in PBS) was added. After incubating for $3.5 \mathrm{~h}$ at $37^{\circ} \mathrm{C}$, the media was replaced with $150 \mu \mathrm{l}$ of MTT solvent $(4 \mathrm{mM} \mathrm{HCl}$ and $0.1 \%$ Nonidet P-40 in isopropanol). After $15 \mathrm{~min}$ of agitation on an orbital shaker, absorbance was read at $570 \mathrm{~nm}$ with a reference filter of $630 \mathrm{~nm}$. The absorbance directly correlates with the MTT formazans formed by mitochondrial dehydrogenases of viable cells. ${ }^{25}$

\section{Statistical Analysis}

The data were analyzed using SPSS version 16.0 for Windows (SPSS, IL, USA).

Variables are reported as the mean \pm s.e.m. Data between groups were compared using the Mann-Whitney $U$-test. For histological inflammation, the mean of the two independent observers' scores was used for analysis. Weight was compared between treatment groups by ANOVA for repeated measurements. Correlations between two variables were evaluated with the Spearman's Rho test. Two-tailed probabilities were calculated and results were considered significant at a value of $P<0.05$.

Figure 1 In vitro and in vivo oxygen $\left(\mathrm{O}_{2}\right)$-dissolving and -releasing capacity of perfluorodecalin (PFD). Baseline $\mathrm{O}_{2}$ tension ( $\left(\mathrm{OO}_{2}\right)$ of $\mathrm{PFD}$ and normal saline are similar. After $5 \mathrm{~min}$ of simple bubbling with $100 \% \mathrm{O}_{2}$ at a rate of $3 \mathrm{l} / \mathrm{min}$, the $\mathrm{PO}_{2}$ of both PFD and normal saline increased approximately by threefold (timepoint 0). During atmospheric exposure, the $\mathrm{PO}_{2}$ of normal saline almost immediately returned to baseline. In contrast, the $\mathrm{PO} \mathrm{O}_{2}$ of $\mathrm{PFD}$ gradually decreased, returning to normal only after $6 \mathrm{~h}$. This reflects the high $\mathrm{O}_{2}$-dissolving capacity of PFD vs normal saline (a). In vivo, intrarectal (IR) administration of oxygenated PFD $\left(\mathrm{O}_{2}-\mathrm{PFD}\right)(0.5 \mathrm{ml})$ significantly reduced the characteristic 'physiological hypoxia', which is present in the superficial epithelial monolayer of the colon (b). Representative pimonidazole-stained distal colonic sections $(\times 4)$ are shown, with the lower panel showing the computer detection of the stained area ( $\sim$ mucosal hypoxia) (c). Serial computed tomography (CT) after a single IR administration of 0.5 ml PFD in mice suffering from dextran sodium sulfate (DSS) colitis shows washout of PFD (marked by black arrows) within 1 week (d). ${ }^{\star} P<0.05$, NS, not significant. 
a

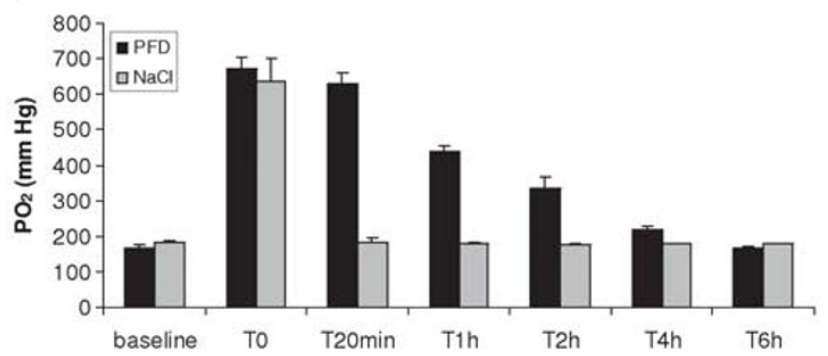

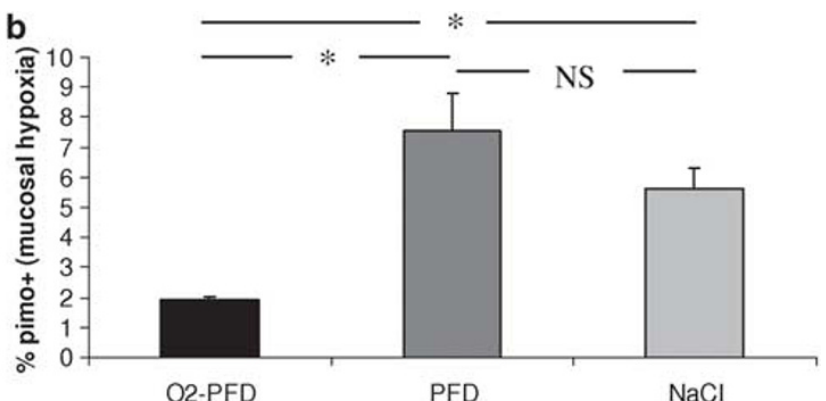

C
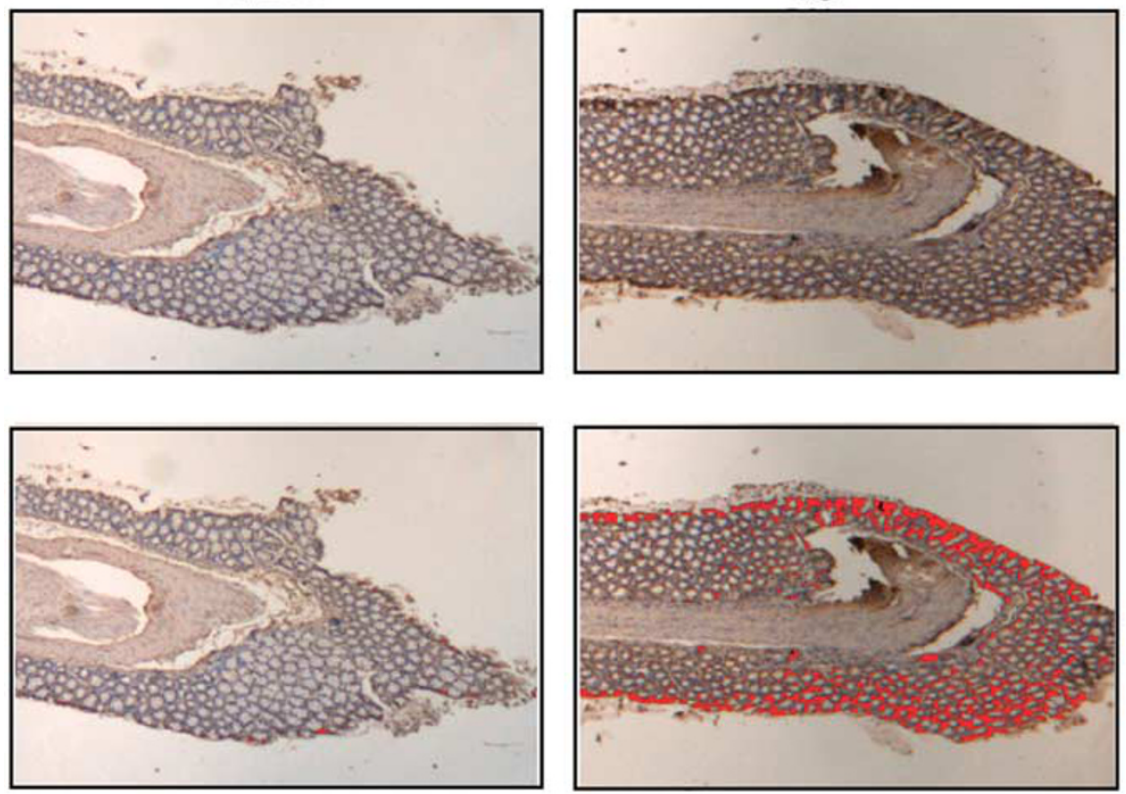

normal saline
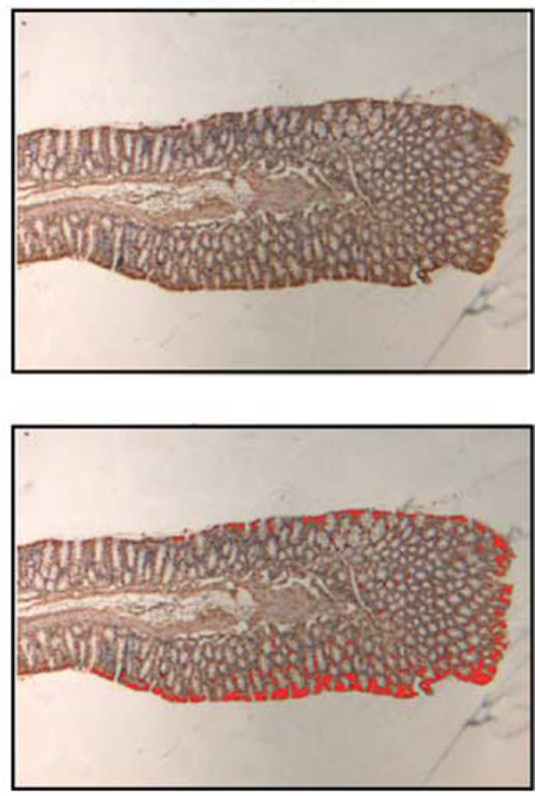

d

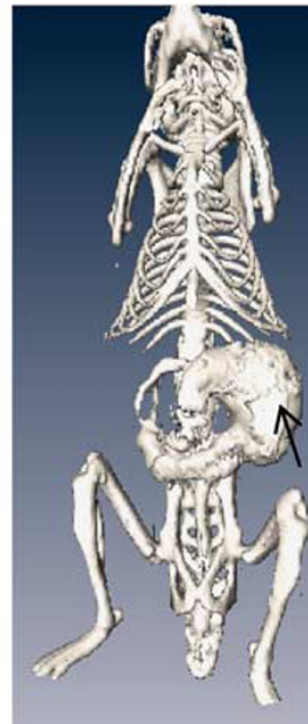

5 minutes

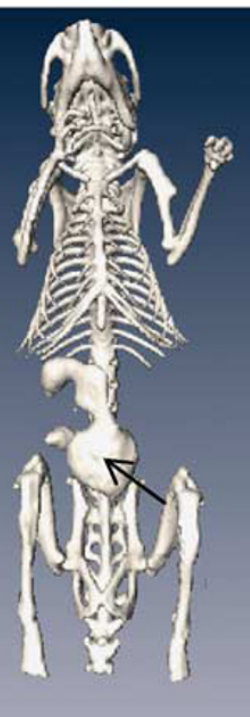

1 hour

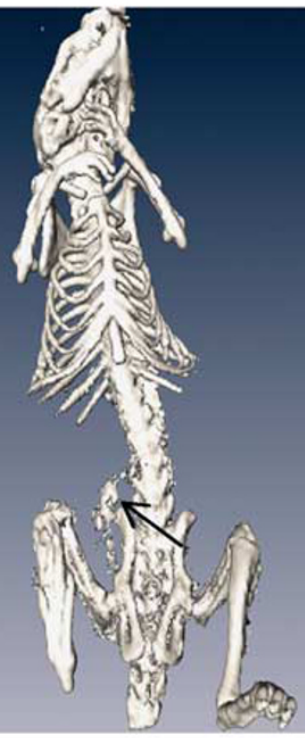

1 day

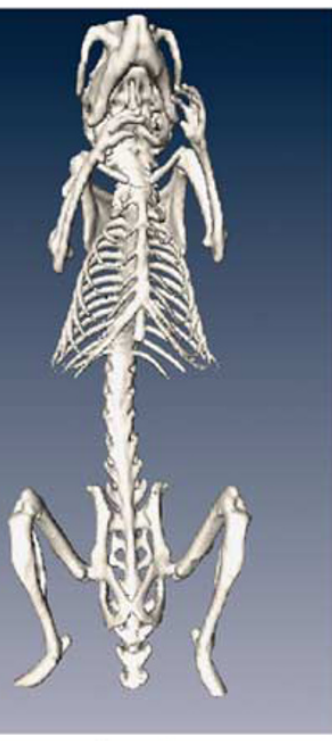

1 week 


\section{RESULTS}

\section{Oxygen-Solubilizing and -Releasing Capacity of Perfluorodecalin}

We first tested the capacity of PFD to function as an $\mathrm{O}_{2}$ carrier to IECs in vitro and in vivo.

PFD was oxygenated by bubbling with $100 \% \mathrm{O}_{2}$ at a rate of $3 \mathrm{l} / \mathrm{min}$ for $5 \mathrm{~min}$. This increased its $\mathrm{PO}_{2}$ level from about $170 \mathrm{~mm} \mathrm{Hg}$ to approximately $700 \mathrm{~mm} \mathrm{Hg}$. When stored in ambient air $\left(21 \% \mathrm{O}_{2}\right)$, the $\mathrm{PO}_{2}$ of the $\mathrm{O}_{2}$-PFD gradually decreased and returned to normal after $6 \mathrm{~h}$. In contrast, identical oxygenation of normal saline (which has a baseline $\mathrm{PO}_{2}$ comparable to $\mathrm{PFD}$ ) also increased its $\mathrm{PO}_{2}$ levels to about $600 \mathrm{mmHg}$, but all $\mathrm{O}_{2}$ was almost immediately released upon return to ambient air, reflecting a very low $\mathrm{O}_{2}$-dissolving capacity (Figure 1a).

To demonstrate colonic mucosal oxygenation by IR administration of $\mathrm{O}_{2}$ PFD in vivo, we utilized a hypoxia detection kit (Hypoxyprobe-1 Plus Kit, NPI), which makes use of pimonidazole as a hypoxia tracer. Pimonidazole was i.p. injected in Sv129 mice $(100 \mathrm{mg} / \mathrm{kg})$, concomitantly with an IR treatment with $0.5 \mathrm{ml}$ of $\mathrm{O}_{2}-\mathrm{PFD}$, non- $\mathrm{O}_{2}-\mathrm{PFD}$ or saline ( $N=2-3$ mice per group). One hour after the pimonidazole injection, the mice were killed and the colon was removed. Pimonidazole was immunohistochemically detected in paraffin-embedded colonic sections. In normal conditions, pimonidazole can be detected in the IECs that line the gut lumen because of the 'physiological hypoxia' in these cells. ${ }^{1}$ Intrarectal administration with $\mathrm{O}_{2}$-PFD highly decreased the accumulation of pimonidazole in this superficial colonic epithelium compared with mice treated with non- $\mathrm{O}_{2}$-PFD (hereafter, simply referred to as PFD) or saline $(P<0.05)$, offering direct evidence for effective mucosal $\mathrm{O}_{2}$ delivery by the $\mathrm{O}_{2}$ solubilized in PFD (Figures $1 \mathrm{~b}$ and $\mathrm{c}$ ).

To follow the washout of IR administered PFD, we used CT. PFD is a high-density liquid that can be easily identified and localized by CT. DSS colitis was induced in three mice. At day 7 (established colitis), mice were administered a single IR injection with $0.5 \mathrm{ml}$ PFD. Five minutes after IR administration, PFD was detected throughout the entire colon. Most of the PFD was still present after $1 \mathrm{~h}$. One day after the administration, traces of PFD were still present. All PFD was cleared after 1 week (Figure 1d).

Rectal Administration of $\mathbf{O}_{\mathbf{2}}$-PFD Protects against Colitis After having shown that twice daily IR treatment with $\mathrm{O}_{2}$-PFD effectively oxygenates the colonic mucosa, we investigated whether this treatment was able to prevent colitis. Treatment began at day 0 and ended at day 7 of DSS administration. Twice daily treatment was given based on our above described in vitro/in vivo IEC oxygenation and IR washout data.

Mice treated with $\mathrm{O}_{2}$-PFD and PFD both had significantly reduced weight loss compared with saline-treated littermates $(P<0.05$; data not shown). The length of the colon, which is a well-known parameter to determine colonic damage, was significantly reduced in all DSS-treated groups compared with control mice. However, colonic shortening was less severe in $\mathrm{O}_{2}$-PFD treated mice $(P<0.05$, compared with both the PFD-treated group and the saline-treated group) (Figure 2a). At the histological level, inflammatory cell infiltration and colonic epithelial ulcerations were least pronounced in mice treated with $\mathrm{O}_{2}-\mathrm{PFD}$, but mice that were treated with PFD also tended to fare better than salinetreated mice (Figures $2 \mathrm{~b}$ and $\mathrm{d}$ ). Strong suppression of TNF- $\alpha$ protein levels was observed in both $\mathrm{O}_{2}$-PFD and PFDtreated mice $(P<0.05$ compared with saline-treated mice) (Figure 2e). A strong correlation was seen between mucosal pimonidazole staining (which directly correlates with the degree of mucosal hypoxia) and the degree of histological inflammation (Spearman's Rho test $=0.81$ ) (Figure 2f). There was a trend toward less stabilization of hypoxiainducible factor (HIF) $-1 \alpha$ in the mucosa of $\mathrm{O}_{2}$-PFD-treated mice compared with saline-treated mice $(P=0.2$; see Supplementary Figure 1).

These results suggest an intrinsic anti-inflammatory effect of the PFD molecule, with a supplemental beneficial outcome upon oxygenation of this molecule.

\section{Rectal Administration of $\mathrm{O}_{2}$-PFD Promotes Healing of Colitis}

In a subsequent experiment, we addressed the question of whether rectal $\mathrm{O}_{2}$-PFD administration accelerated the healing of established colitis. After 7 days of DSS treatment, DSS was withdrawn and treatment groups were randomized to assure equal clinical disease activity at the start of treatment (Figure 3a). Treatment with $\mathrm{O}_{2}$-PFD resulted in a significantly better post-DSS weight evolution compared with saline-treated mice $(P<0.05)$ and a trend of better weight evolution compared with mice that were treated with PFD $(P=0.083)$. Weight loss of mice that were treated with PFD initially followed that of saline-treated mice, but by the final day of treatment (day 11), the PFD group also showed a trend of reduced weight loss $(P=0.12$ at day 11; Figure $3 a)$.

At the histological level, less infiltration of inflammatory cells was observed in both the $\mathrm{O}_{2}$-PFD and the PFD groups compared with saline-treated mice. In line with this, MPO activity (a measure for neutrophil infiltration) was significantly decreased in the distal colon of $\mathrm{O}_{2}$-PFD- and PFD-treated mice compared with saline-treated mice (Figures 3c, d and e). In contrast, colonic epithelial ulcerations were highly reduced in the $\mathrm{O}_{2}$-PFD group $(P<0.01$ compared with the saline-treated group), but not at all in mice treated with PFD (Figures $3 b$ and $d$ ). As a consequence of these differences in damage of the colonic epithelial monolayer, the DSS-induced intestinal barrier dysfunction (demonstrated by the presence of orally administered FITC-dextran in the serum) was more pronounced in saline- and PFD-treated mice compared with $\mathrm{O}_{2}$-PFD-treated mice (Figure 3f). 


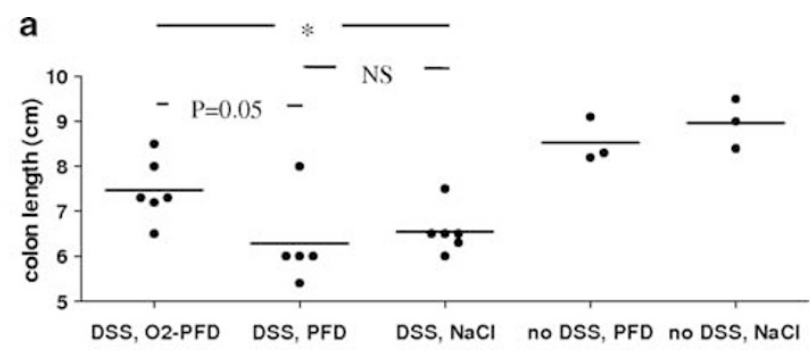

b

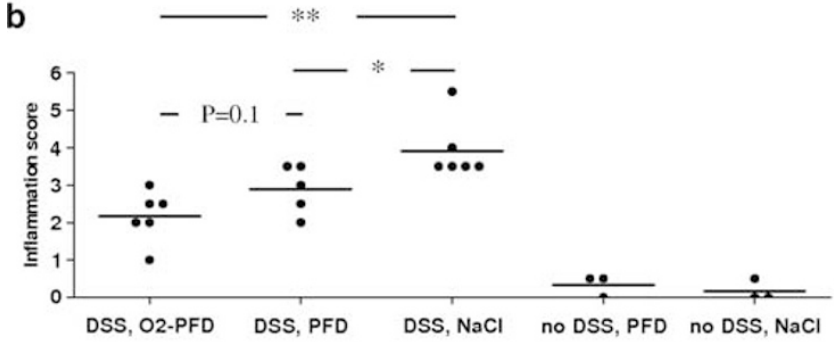

d

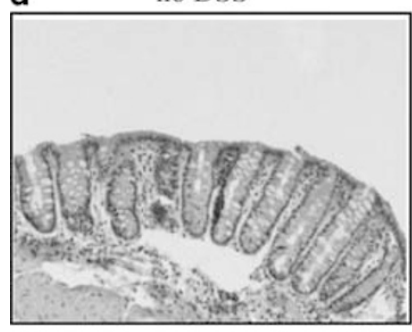

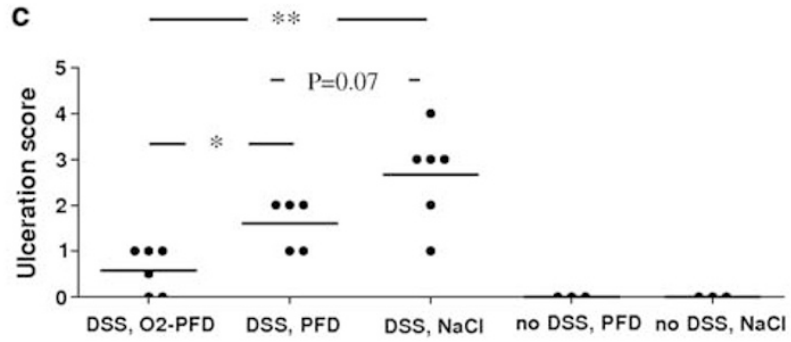

DSS, PFD

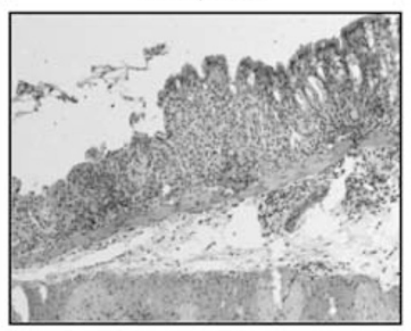

DSS, $\mathrm{NaCl}$

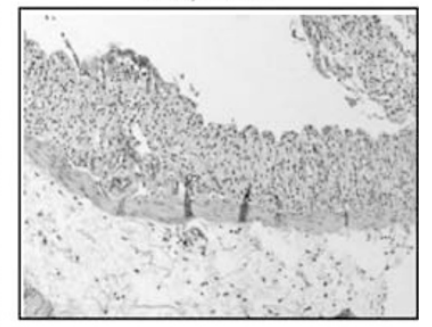

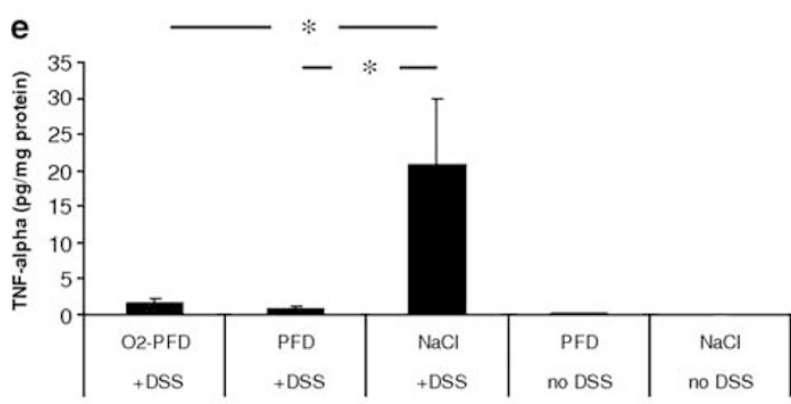

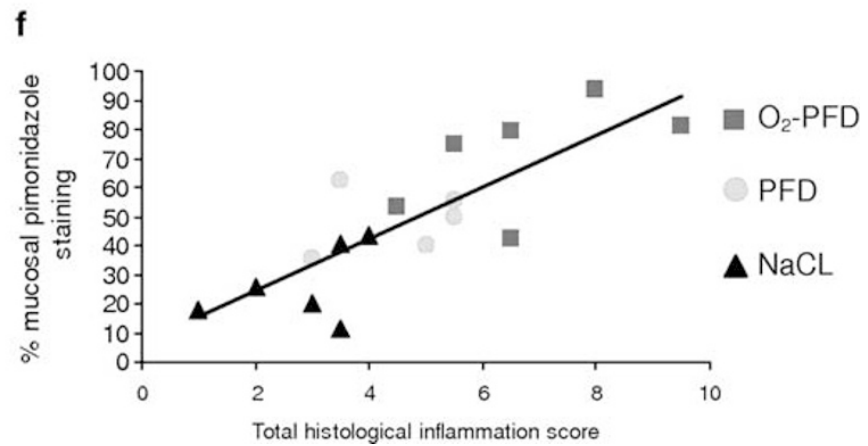

Figure 2 Rectal administration of oxygenated perfluorodecalin (PFD) is protective against colitis. Twice daily intrarectal (IR) treatment with $0.5 \mathrm{ml}$ of oxygenated PFD $\left(\mathrm{O}_{2}-\mathrm{PFD}\right)$ led to reduced shortening of colon length compared with PFD- and saline-treated mice $(P<0.05)$, indicating that reduced colonic damage took place in this group after dextran sodium sulfate (DSS) administration (a). Both inflammatory cell infiltration (b) and colonic ulcerations (c) were reduced in PFD-treated mice compared with saline-treated mice, with a supplemental reduction of these parameters when PFD was oxygenated before administration. The pictures (d) are representative hematoxylin and eosin-stained pictures $(\times 200)$ of the different treatment groups at day 7 of DSS administration At the cytokine level, colonic tumor necrosis factor-alpha (TNF- $\alpha$ ) protein levels were highly suppressed in PFD- and $\mathrm{O}_{2}$-PFD-treated mice animals compared with saline-treated mice $(\mathbf{e})$. A strong positive correlation (Spearman's Rho test $=0.81$ ) was found between the degree of colonic histological inflammation and the severity of mucosal hypoxia (f). ${ }^{*} P<0.05,{ }^{*} P<0.01$, NS, not significant.

The above findings again suggest an intrinsic antiinflammatory effect of the PFD molecule, but a strong supplemental effect of oxygenation on epithelial ulcer healing.

\section{Oxygenated PFD Rescues IECs from Hypoxia-Induced Apoptosis and Stimulates IEC Proliferation During Hypoxia In Vitro and In Vivo}

DSS affects the epithelium by inducing apoptosis and inhibiting proliferation of IECs, leading to barrier disruption and subsequent inflammation. ${ }^{26,27}$ We showed that increased inflammation leads to enhanced mucosal hypoxia. Hypoxia may boost the disease process, as it promotes apoptosis and suppresses proliferation of epithelial cells. ${ }^{28-30}$ As our above results showed that mucosal oxygenation by $\mathrm{O}_{2}$-PFD has a strong beneficial effect on the preservation of the colonic epithelial cell surface, we investigated the effect of $\mathrm{O}_{2}$-PFD on both hypoxia-induced IEC apoptosis and IEC proliferation. 

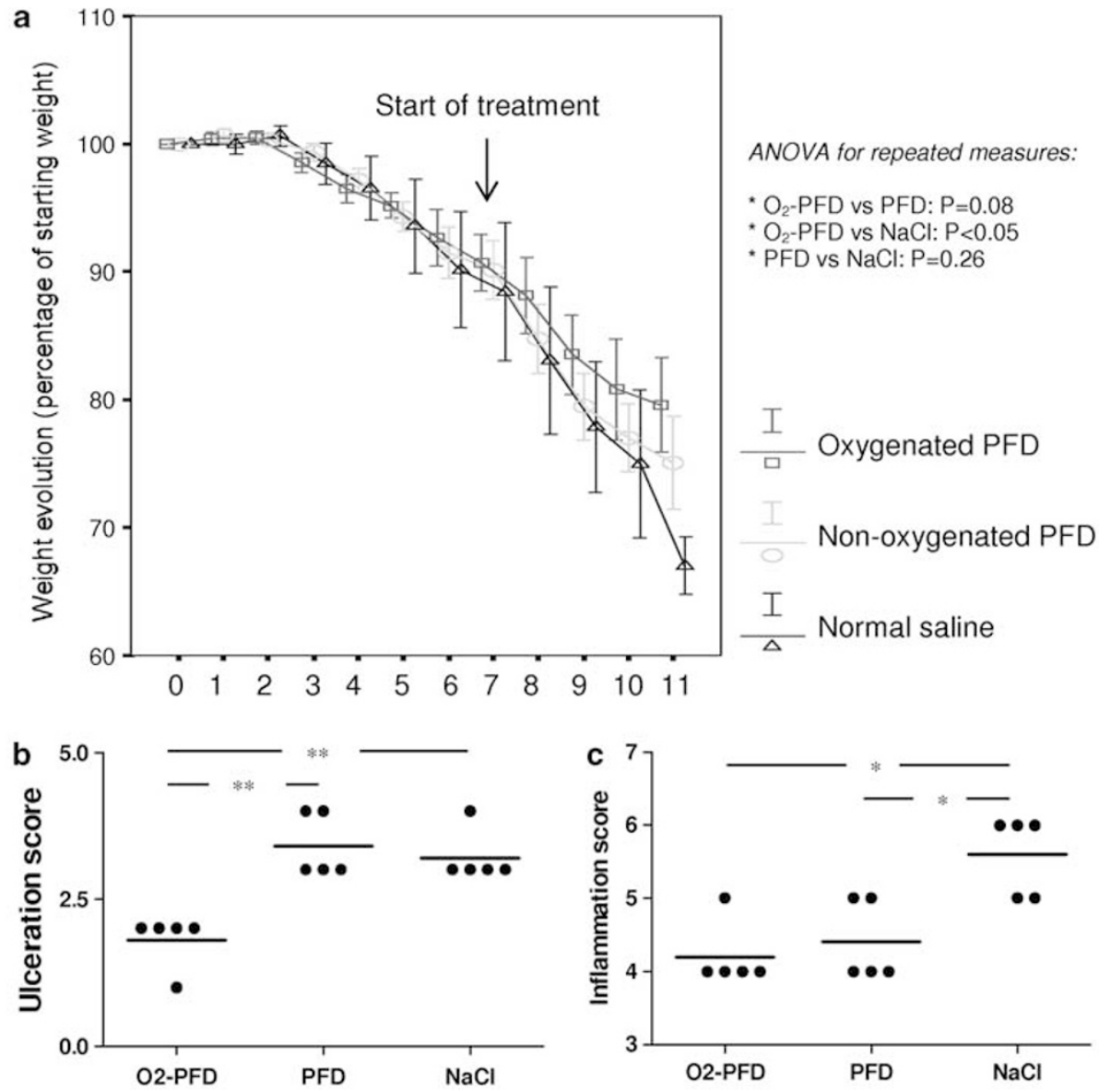

d

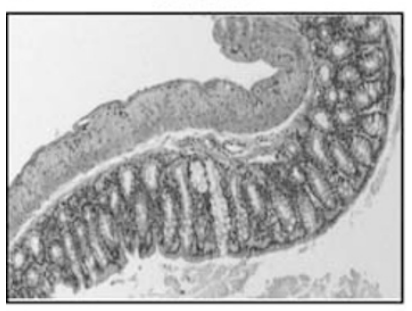

e

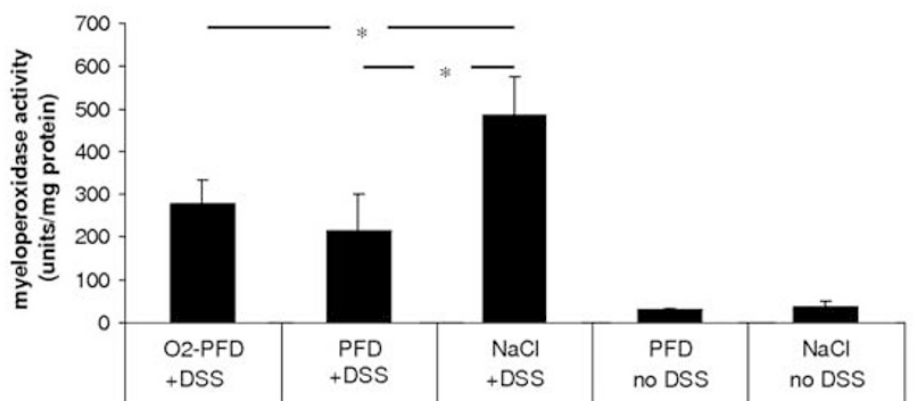

DSS, $\mathrm{O}_{2}-\mathrm{PFD}$

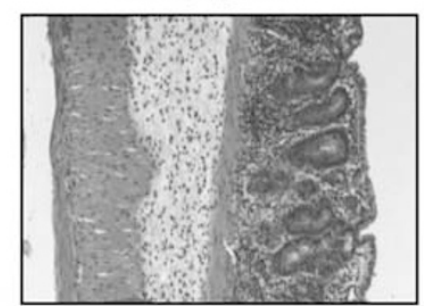

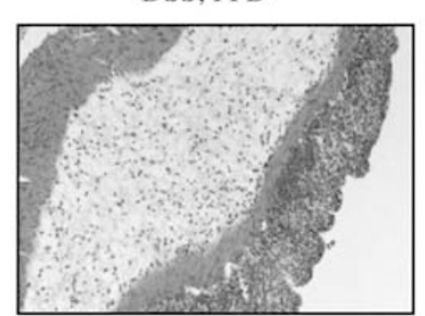

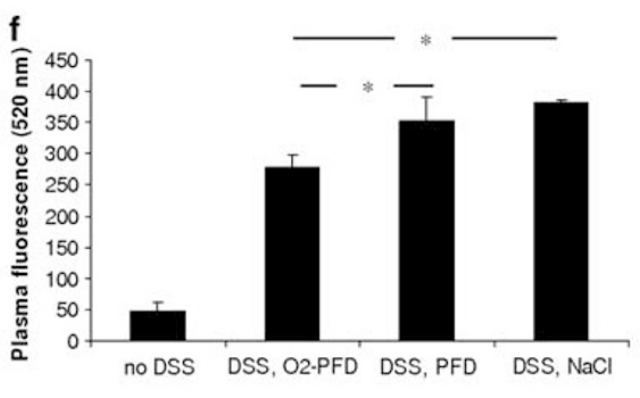

Figure 3 Rectal administration of oxygenated PFD $\left(\mathrm{O}_{2}-\mathrm{PFD}\right)$ accelerates recovery from colitis. Twice daily intrarectal (IR) treatment with $0.5 \mathrm{ml}$ of $\mathrm{O}_{2}-\mathrm{PFD}$ led to a favorable post-dextran sodium sulfate (DSS) weight-evolution compared with non- $\mathrm{O}_{2}$-PFD- and saline-treatment (a). At the histological level, fewer ulcerations (b) and less inflammatory cell infiltration (c) were noted in the $\mathrm{O}_{2}$-PFD group compared with the saline group, whereas PFD-treated mice showed a similar reduction of inflammatory cell infiltration, but no reduction in ulcerations of the epithelial cell surface. In line with this, both treatment with $\mathrm{O}_{2}-\mathrm{PFD}$ and PFD reduced myeloperoxidase (MPO) levels (which measures neutrophil activity) (e), but improved intestinal epithelial barrier function was only evident in the $\mathrm{O}_{2}$-PFD-treated group (f). The pictures in (d) show representative hematoxylin and eosin-stained pictures $(\times 200)$ of the different treatment groups at day 11,4 days after DSS administration. ${ }^{\star} P<0.05,{ }^{*} P<0.01$. 

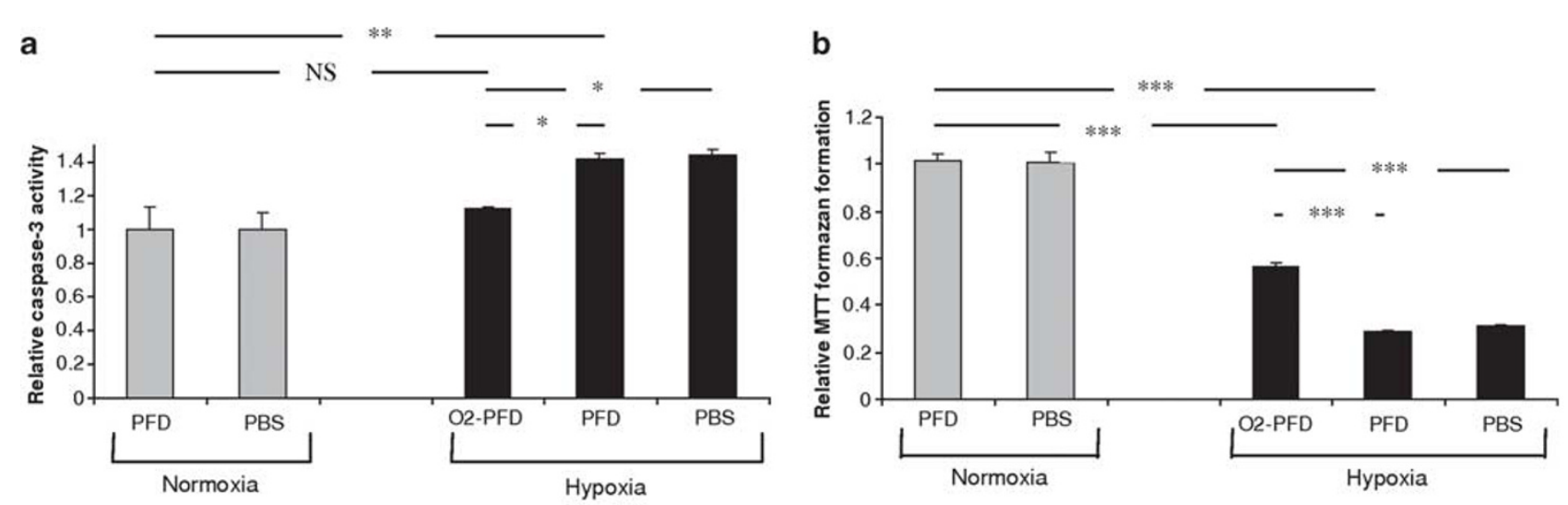

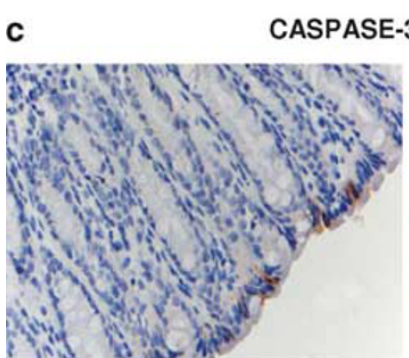

No DSS

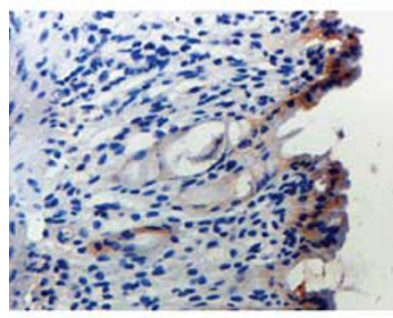

DSS, PFD

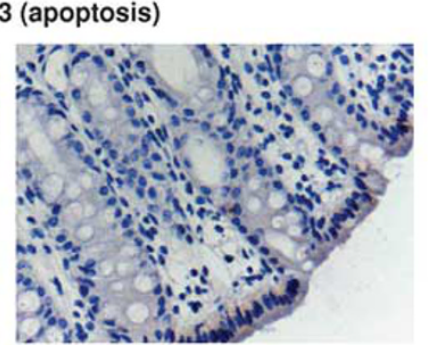

DSS, $\mathrm{O}_{2}$-PFD

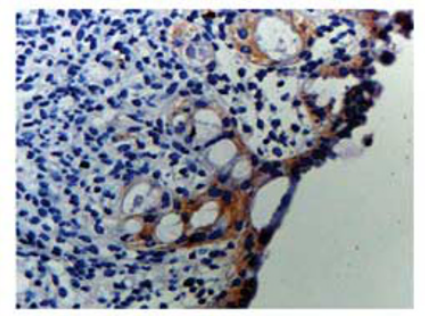

DSS, $\mathrm{NaCl}$

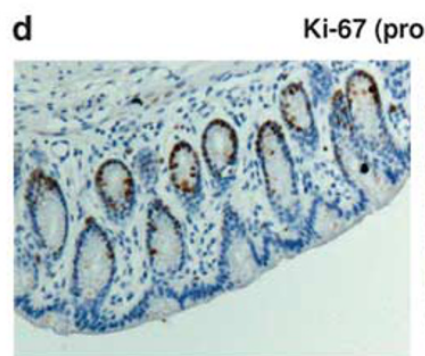

No DSS

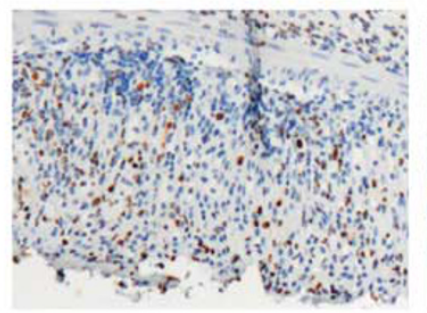

DSS, PFD

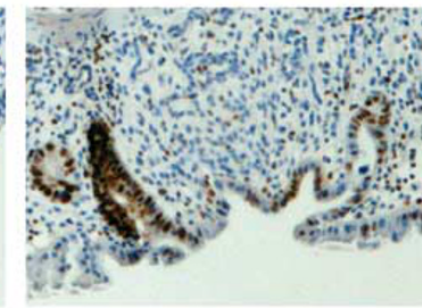

DSS, $\mathrm{O}_{2}-\mathrm{PFD}$

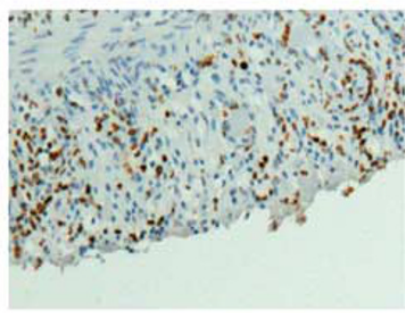

DSS, $\mathrm{NaCl}$
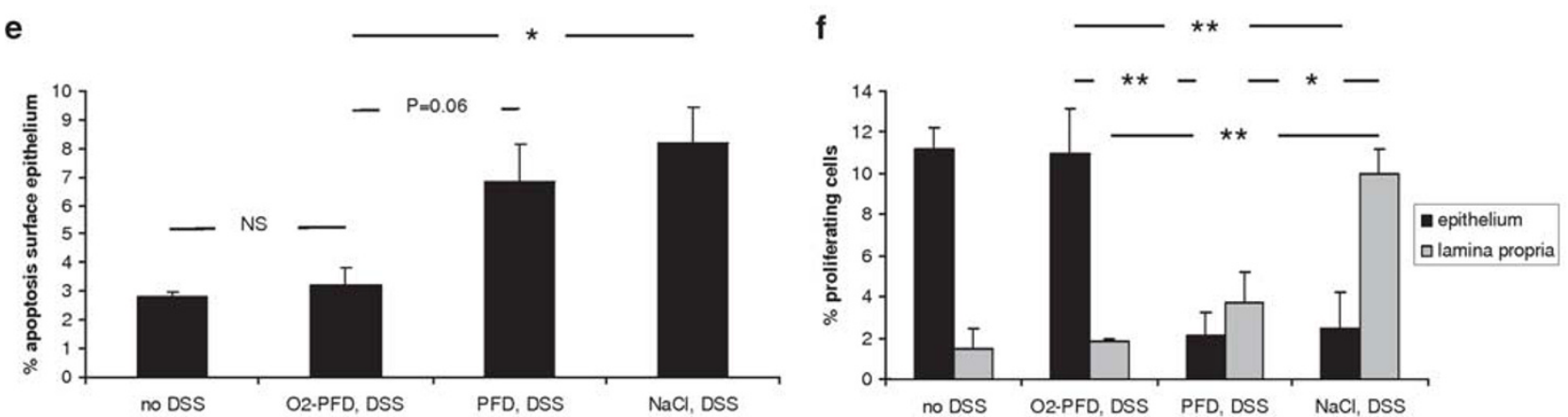

Figure 4 Oxygenated perfluorodecalin (PFD) reduces intestinal epithelial apoptosis and stimulates intestinal epithelial proliferation during (inflammatory) hypoxia. In vitro, adding oxygenated PFD $\left(\mathrm{O}_{2}-\mathrm{PFD}\right)$ to the cell medium of $\mathrm{HT} 29$ intestinal epithelial cells (IECs) led to reduced hypoxia-induced apoptosis compared with PFD- or phosphate-buffered saline (PBS)-treated cells (a), as well as improved IEC proliferation (b). ( $1 \% \mathrm{O}_{2}$ conditions were achieved with a hypoxic chamber). In vivo, twice daily intrarectal (IR) administration of $\mathrm{O}_{2}-\mathrm{PFD}(0.5 \mathrm{ml}$ per administration, starting from day 0$)$ clearly protected colonocytes against apoptosis, measured at day 7 of dextran sodium sulfate (DSS) colitis (caspase-3 staining, $\times 200)(\mathbf{c}, \mathbf{e})$. When $\mathrm{O}_{2}$-PFD treatment was started after colitis was established (day 7) and continued until day 11, it led to increased colonocyte proliferation at the epithelial surface and reduced proliferation of inflammatory cells within the lamina propria compared with normal saline-treated mice. Treatment with non- $\mathrm{O}_{2}-\mathrm{PFD}$ also led to reduced proliferation of inflammatory cells compared with saline-treated mice, but not to an improved proliferation at the epithelial surface (Ki-67 staining, $\times 200)(\mathbf{d}, \mathbf{f})$.

Only $\mathrm{O}_{2}$-PFD and not PFD was able to suppress hypoxiainduced IEC apoptosis (Figure 4a and Supplementary Figure 2) and to stimulate hypoxia-induced IEC proliferation in vitro (Figure $4 \mathrm{~b}$ ). In vivo, colonic staining for cleaved caspase-3 (an apoptotic executioner) was almost exclusively located at the surface epithelium. Some single apoptotic cells were seen in healthy control animals. After 7 days of DSS (preventive setting), increased caspase-3 staining was seen in 
clusters of surface colonocytes of PFD- and saline-treated mice, but not in $\mathrm{O}_{2}$-PFD-treated mice (Figures $4 \mathrm{c}$ and e), suggesting a strong anti-apoptotic action of locally administered $\mathrm{O}_{2}$-PFD on IECs in vivo.

In vivo cell proliferation was assessed after a 4-day treatment with $\mathrm{O}_{2}$-PFD, PFD or normal saline following colitis induction. Colonic staining for Ki-67 (proliferation marker) was located in the basal crypt epithelial cells of control animals. After DSS (day 11, curative setting), the total amount of Ki-67 staining was not different in $\mathrm{O}_{2}$-PFD-treated animals $v s$ saline-treated animals, but the location pattern was different. In $\mathrm{O}_{2}$-PFD-treated mice, Ki-67 was mainly found at the epithelial surface, whereas in saline-treated mice, Ki-67 staining was most prominent in the inflammatory cells. Thus, a clear mucosal healing process was present in the $\mathrm{O}_{2}$-PFD-treated group, whereas active inflammation was present in the saline-treated group. Animals treated with PFD had reduced proliferation of inflammatory cells compared with saline-treated animals, but no increase in proliferation of cells at the surface epithelium. Thus, PFD possessed intrinsic anti-inflammatory effects, but the direct effect on healing of the intestinal epithelial barrier was mediated by the $\mathrm{O}_{2}$ captured in $\mathrm{O}_{2}$-PFD (Figures $4 \mathrm{~d}$ and $\mathrm{f}$ ).

\section{DISCUSSION}

In this study, we report a beneficial effect of IR administration of $\mathrm{O}_{2}$-PFD on experimental colitis, both in preventive and therapeutic settings.
The presence of decreased $\mathrm{O}_{2}$ supply in the inflamed mucosa of IBD patients has been described previously, but little attention has been given to the role of this mucosal hypoxia in the pathogenesis and the maintenance of gut inflammation. ${ }^{3}$ However, it is clear that mucosal hypoxia may have a significant impact on the intestinal epithelial barrier function, which is known to be highly defective in IBD. This is because the colonocytes that form the barrier of the gut are the first cells to suffer from mucosal hypoxia during inflammation. These cells have a marginal baseline $\mathrm{O}_{2}$ supply, and if $\mathrm{PO}_{2}$ levels decrease below a critical threshold, reduced proliferation and increased apoptosis occurs, respectively, resulting in delayed mucosal healing and further disruption of the epithelial barrier (Figure 5)., ${ }^{1,2}$

An impaired intestinal barrier function directly exposes the inflammatory cells within the lamina propria to deleterious substances present within the lumen of the gut, prolonging the inflammation. Therefore, molecules that protect or restore intestinal epithelial barrier function are of particular interest in the treatment of IBD. In fact, the ability of anti-TNF therapy to induce complete mucosal healing with full restoration of the gut epithelial architecture in IBD has been attributed to its direct protective effect on the gut epithelium. ${ }^{31-33}$

Similar to all other cells, the intestinal epithelium responds to low $\mathrm{O}_{2}$ levels by stabilizing HIF-1, a transcription factor that induces the expression of a number of barrierprotective genes. We and others have previously shown that

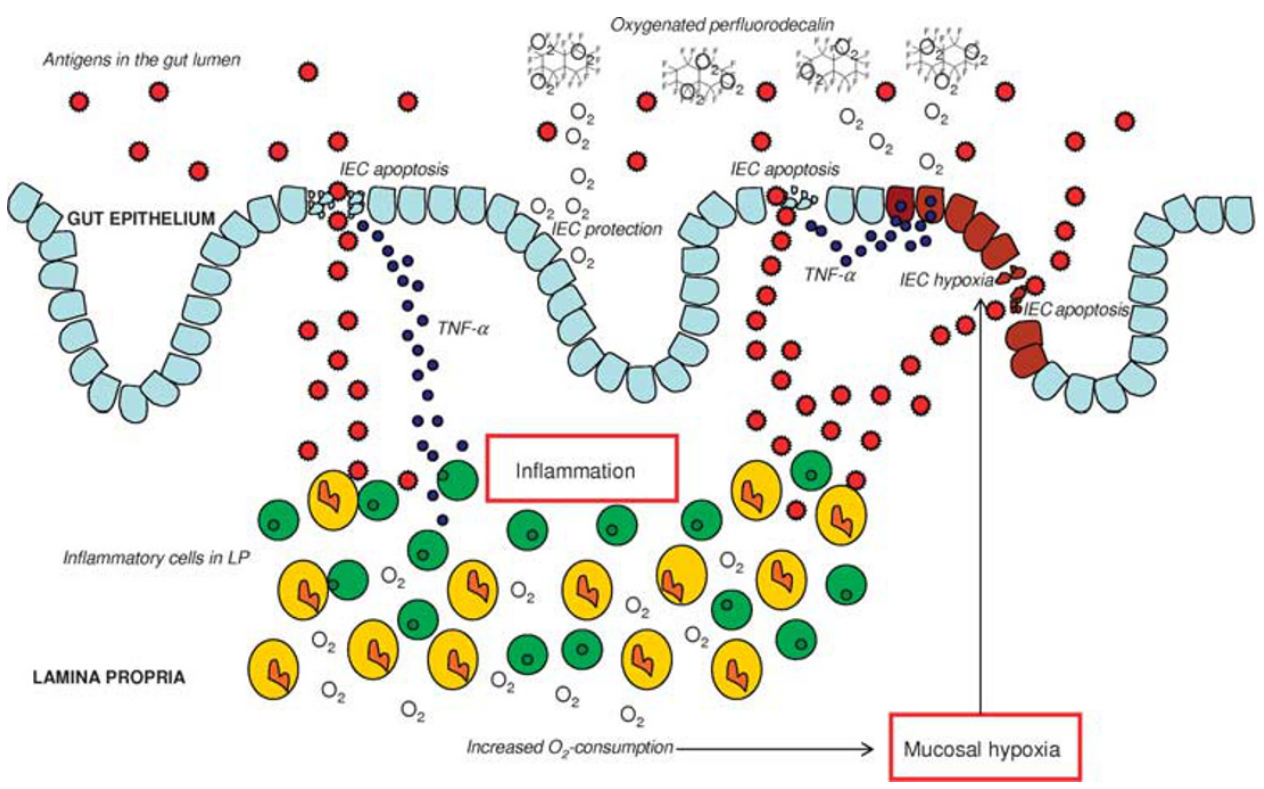

Figure 5 Proposed mechanism of action of oxygenated perfluorodecalin (PFD) in inflammatory bowel disease. Inflammatory bowel disease is characterized

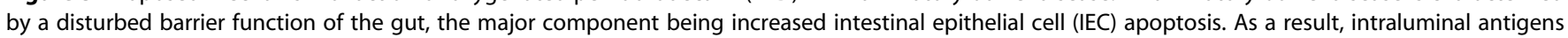
freely cross the epithelial monolayer to get in contact with the lamina propria immune system. This worsens the inflammatory process, leading to massive infiltration of inflammatory cells that all consume oxygen $\left(\mathrm{O}_{2}\right)$ for their function and survival. The resulting mucosal hypoxia mainly affects the IEC's, as these cells already have a very low steady-state $\mathrm{O}_{2}$ tension due to their marginal blood supply. Severe hypoxia may lead to IEC death and further disruption of the gut barrier. Moreover, both hypoxia and inflammation stimulate the release of tumor necrosis factor-alpha (TNF- $\alpha$ ), which also has a proapoptotic action on the gut epithelium. Intraluminal administration of oxygenated PFD $\left(\mathrm{O}_{2}-\mathrm{PFD}\right)$ directly delivers $\mathrm{O}_{2}$ to the IEC's and suppresses inflammatory cytokines such as TNF- $\alpha$. In this way, $\mathrm{O}_{2}$-PFD promotes healing of IBD. 
pharmacological boosting of this HIF-1 stabilization by prolyl hydroxylase-inhibiting compounds promotes the resolution of intestinal inflammation in a variety of animal models of IBD. ${ }^{7}$

The current study shows that IR administration of $\mathrm{O}_{2}-\mathrm{PFD}$ may be an alternative strategy to protect the gut epithelium against the deleterious effects of severe hypoxia during inflammation and that this treatment promotes the resolution of inflammation as well. $\mathrm{O}_{2}$-PFD inhibits colonocyte apoptosis and promotes colonocyte proliferation by oxygenating the intestinal mucosa during (inflammatory) hypoxia. In this way, healing of the injured epithelial surface and clinical recovery from colitis could be accelerated (Figure 5).

The beneficial effect of $\mathrm{O}_{2}$-PFD in our colitis model was not exclusively attributable to a better oxygenation of the gut mucosa. Perfluorodecalin itself had a direct antiinflammatory effect, regardless of whether it was oxygenated. In line with our results, PFCs have previously been shown to reduce the levels of cytokines and chemokines (including TNF- $\alpha$ ) and inhibit neutrophil activation and infiltration during lung inflammation. ${ }^{34,35}$ Our data strongly suggest that a similar action profile is present in the gut. Although the exact mechanism behind this direct anti-inflammatory effect remains to be elucidated, some interesting hypotheses have been put forward. For example, it has been nicely demonstrated that perfluorochemicals are able to function as a tight physical barrier. ${ }^{34,36}$ Hence, IR PFD may form an impermeable film over the colonic epithelial monolayer and contribute to the colonic barrier function. This might explain why mice treated with IR PFD show a reduced inflammatory response to the DSS-induced colonic epithelial barrier disruption compared with mice treated with IR saline, as the presence of the high-density PFD prevents the massive influx of intraluminal antigens and flora into the lamina propria.

Other mechanisms by which PFCs may directly suppress inflammation have been described (eg. inhibition of inducible nitric oxide synthase, suppression of the COX2$\mathrm{PGE}_{2}$ pathway), and we cannot exclude that they have contributed to the observed effects in our study. ${ }^{37,38}$

The oxygenation- and anti-inflammatory capacity of PFCs has led to their pre-clinical and clinical evaluation in numerous pathological conditions including shock, brain injury, anemia and cardiac disease. ${ }^{39}$ As far as the authors are aware, the present study is the first report on the successful use of PFCs in inflammatory bowel disease.

Beside their potential to act as $\mathrm{O}_{2}$ carriers, PFC liquids also seem useful as delivery vehicles for local administration of biological agents, including antibiotics and gene vectors. ${ }^{40}$ Therefore, we believe that future research in the applicability of PFCs for local delivery of therapeutic agents to the gut would be useful.

In summary, we show that local administration of $\mathrm{O}_{2}-\mathrm{PFD}$ is effective in experimental colitis by (1) intrinsic antiinflammatory effects of PFD and (2) stimulation of colonocyte survival and proliferation during inflammatory hypoxia. These findings warrant clinical trials to determine the applicability and effectiveness of locally administered intraluminal $\mathrm{O}_{2}$-PFD in hypoxic inflammatory diseases such as IBD.

Supplementary Information accompanies the paper on the Laboratory Investigation website (http://www.laboratoryinvestigation.org)

\section{ACKNOWLEDGEMENTS}

We thank Dr Steven Staelens and Steven Deleye (Medical Signal and Image Processing group, Ghent University-IBBT, Ghent, Belgium) for acquisition of the $\mu \mathrm{CT}$ images. This study was supported by the concerted Grant GOA2001/12051501 of Ghent University, Belgium, and by a Grant of the National Fund for Scientific Research (FWO Grant A2/5-11716).

\section{DISCLOSURE/CONFLICT OF INTEREST}

The authors declare no conflict of interest.

1. Taylor CT, Colgan SP. Hypoxia and gastrointestinal disease. J Mol Med 2007;85:1295-1300.

2. Hindryckx P, Waeytens $A$, Laukens $D$, et al. Absence of placental growth factor blocks dextran sodium sulfate-induced colonic mucosal angiogenesis, increases mucosal hypoxia and aggravates acute colonic injury. Lab Invest 2010;90:566-576.

3. Ibrahim $\mathrm{CB}$, Aroniadis $\mathrm{OC}$, Brandt $\mathrm{LJ}$. On the role of ischemia in the pathogenesis of IBD: a review. Inflamm Bowel Dis 2010;16:696-702.

4. Colgan SP, Taylor CT. Hypoxia: an alarm signal during intestinal inflammation. Nat rev Gastroenterol Hepatol 2010;7:281-287.

5. Taylor CT, Dzus AL, Colgan SP. Autocrine regulation of epithelial permeability by hypoxia: role for polarized release of tumor necrosis factor alpha. Gastroenterology 1998;114:657-668.

6. Taylor CT. Regulation of intestinal epithelial gene expression in hypoxia. Kidney Int 2004;66:528-531.

7. Hindryckx P, Laukens D, De Vos M. Boosting the hypoxia-induced adaptive response in inflammatory bowel disease: a novel concept of treatment. Inflamm Bow Dis; published online 16 December 2010 (e-pub ahead of print).

8. Rachmilewitz D, Karmeli F, Okon E, et al. Hyperbaric oxygen: a novel modality to ameliorate experimental colitis. Gut 1998;43:512-518.

9. Takeshima F, Makiyama K, Doi T, et al. Hyperbaric oxygen as adjunct therapy for Crohn's intractable enteric ulcer. Am J Gastroenterol 1999;94:3374-3375.

10. Weisz G, Lavy A, Adir $Y$, et al. Modification of in vivo and in vitro TNF-alpha, IL-1, and IL-6 secretion by circulating monocytes during hyperbaric oxygen treatment in patients with perianal Crohn's disease. J Clin Immunol 1997;17:154-159.

11. Noyer CM, Brandt LJ. Hyperbaric oxygen therapy for perineal Crohn's disease. Am J Gastroenterol 1999;94:318-321.

12. Riess JG, Le Blanc M. Solubility and transport phenomena in perfluorochemicals relevant to blood substitution and other biomedical applications. Pure Appl Chem 1982;54:2383-2406.

13. Spahn DR. Blood substitutes artificial oxygen carriers: perfluorocarbon emulsions. Crit Care 1999;3:93-97.

14. Waschke KF, Lenz C. [Biomedical applications of artificial oxygen carriers]. Infusionsther Transfusionsmed 1999;26:31-36.

15. Lowe KC. Fluorinated blood substitutes and oxygen carriers. J Fluor Chem 2001;109:59-65.

16. Geyer RP. Perfluorochemicals as oxygen transport vehicles. Biomater Artif Cells Artif Organs 1988;16:31-49.

17. Tandara AA, Mustoe TA. Oxygen in wound healing-more than a nutrient. World J Surg 2004;28:294-300.

18. Davis CS, Cazzaniga AL, Ricotti $C$, et al. Topical oxygen emulsion: a novel wound therapy. Arch Dermatol 2007;143:1252-1256.

19. O'Donnell KA, Caty MG, Zheng $S$, et al. Oxygenated intraluminal perfluorocarbon protects intestinal muscosa from ischemia/ reperfusion injury. J Pediatr Surg 1997;32:361-365.

20. Yamamoto N, Unno N, Mitsuoka $\mathrm{H}$, et al. Peritoneal lavage with oxygenated perfluorochemical improves hemodynamics, intestinal 
injury, and survival in a rat model of severe hemorrhagic shock and resuscitation. Shock 2005;24:171-176.

21. Shinzeki M, Takeyama $Y$, Ueda $T$, et al. Intraperitoneal administration of oxygenated perfluorochemical inhibits bacterial translocation associated with severe acute pancreatitis. Kobe J Med Sci 2003;49:17-24.

22. Van der Sluis M, De Koning B, De Bruijn A, et al. Muc2-deficient mice spontaneously develop colitis, indicating that MUC2 is critical for colonic protection. Gastroenterology 2006;131:117-129.

23. Tambuwala MM, Cummins EP, Colin R, et al. Loss of prolyl hydroxylase1 protects against colitis through reduced epithelial cell apoptosis and increased barrier function. Gastroenterology 2010;139: 2093-2101.

24. Imhof A, Heinzer I. Continuous monitoring of oxygen concentrations in several systems for cultivation of anaerobic bacteria. J Clin Microbiol 1996;34:1646-1648.

25. van de Loosdrecht $A A$, Beelen $R H$, Ossenkoppele $G$, et al. $A$ tetrazolium-based colorimetric MTT assay to quantitate human monocyte mediated cytotoxicity against leukemic cells from cell lines and patients with acute myeloid leukemia. J Immunol Methods 1994;174:311-320.

26. Tessner TG, Cohn SM, Schloemann S, et al. Prostaglandins prevent decreased epithelial cell proliferation associated with dextran sodium sulfate injury in mice. Gastroenterology 1998;115:874-882.

27. Boismenu R, Chen Y, Chou K, et al. Orally administered RDP58 reduces the severity of dextran sodium sulphate induced colitis. Ann Rheum Dis 2002;61:19-24.

28. Sukhotnik I, Helou H, Mogilner EJ, et al. Oral arginine improves intestinal recovery following ischemia-reperfusion injury in rat. Pediatr Surg Int 2005;21:191-196.

29. Ikeda $H$, Suzuki $Y$, Suzuki M, et al. Apoptosis is a major mode of cell death caused by ischaemia and ischaemia/reperfusion injury to the rat intestinal epithelium. Gut 1998;42:530-537.
30. Biswas S, Roy S, Banerjee J, et al. Hypoxia inducible microRNA 210 attenuates keratinocyte proliferation and impairs closure in a murine model of ischemic wounds. Proc Natl Acad Sci USA 2010;107: 6976-6981.

31. Zeissig S, Bojarski C, Buergel N, et al. Downregulation of epithelial apoptosis and barrier repair in active Crohn's disease by tumour necrosis factor alpha antibody treatment. Gut 2004;53:1295-1302.

32. Marini M, Bamias G, Rivera-Nieves J, et al. TNF- $\alpha$-neutralization ameliorates the severity of murine Crohn's-like ileitis by abrogation of intestinal epithelial cell apoptosis. Proc Natl Acad Sci USA 2003; 100:8366-8371.

33. Fries W, Muja C, Crisafulli C, et al. Infliximab and etanercept are equally effective in reducing enterocyte apoptosis in experimental colitis. Int J Med Sci 2008;5:169-180.

34. Lehmer HJ. Anti-inflammatory effects of perfluorocarbon compounds. Expert Rev Respir Med 2008;2:273-289.

35. Colton DM, Till GO, Johnson KJ, et al. Neutrophil accumulation is reduced during partial liquid ventilation. Crit Care Med 1998;26: 1716-1724.

36. Heard SO, Puyana JC. The anti-inflammatory effects of perfluorocarbons: let's get physical. Crit Care Med 2000;28:1241-1242.

37. Chang LP, Lai YS, Wu CJ, et al. Liquid perfluorochemical inhibits inducible nitric oxide synthase expression and nitric oxide formation in lipopolysaccharide-treated RAW 264.7 macrophages. J Pharmacol Sci 2009;111:147-154.

38. Chang $\mathrm{H}$, Kuo FC, Lai YS, et al. Inhibition of inflammatory responses by FC-77, a perfluorochemical, in lipopolysaccharide-treated RAW 264.7 macrophages. Intensive Care Med 2005;31:977-984.

39. Castro $\mathrm{Cl}$, Briceno JC. Perfluorocarbon-based oxygen carriers: review of products and trials. Artif Organs 2010;34:622-634.

40. Lehmler HJ. Perfluorocarbon compounds as vehicles for pulmonary drug delivery. Expert Opin Drug Deliv 2007;4:247-262. 